\title{
Characterization of 1-3 piezoelectric polymer composites - a numerical and analytical evaluation procedure for thickness mode vibrations
}

\author{
C.V. Madhusudhana Rad; G.Prasad $\dagger$ \\ Department of Physics, Osmania University, Hyderabad - 500004 A.P, India \\ Received August 13, 2009, in final form February 23, 2010
}

\begin{abstract}
Biomedical transducers widely employ piezoceramic polymer composites with 1-3 connectivity. The research is aimed at determining the effective material properties of these composites in the micrometer scale by simulation. Volume fraction of piezoceramic in the composite plays an important role in composite material properties as studied by several researchers. It is also noted that the fiber aspect ratio $(a / l)$ also affects the composite material properties. Therefore it is intended to determine the effective material properties both analytically and by simulation using computer simulation software program ANSYS which implements finite element method (FEM). In the present work piezoelectric fiber composites are modeled, analyzed and then the results are verified by using analytical equations. Important conclusions are drawn to select the piezocomposite materials for transducer applications.
\end{abstract}

Key words: piezoelecticity, piezoelectic materials, electromechanical effects, Piezoelectric transducers, Finite element methods

PACS: 77.65.-j, 77.84.-s, 77.65.-j, 43.38.Fx, 47.11.Fg

\section{Introduction}

Piezoelectric composites have attracted the attention of many researchers for the past several decades due to their striking features in practical applications in ultrasonic transducers. Piezoelectric transducers convert electrical signals into mechanical signals and vice versa. Piezocomposites are widely used in many fields such as ultrasonic transducers, biomedical sensors, MEMS such as water purity detection sensors etc. Ferroelectric ceramics have been extensively employed in a verity of such sensors and actuators 1]. They serve as transmitters and receivers in the imaging systems for sonar, medical, and NDE (nondestructive evaluation) applications, as well as in non-imaging applications like SAW (surface acoustic wave) devices in signal processing. In such applications, bulk ferroelectric ceramic materials have certain shortcomings. Piezoceramics have very high electromechanical coupling coefficient $(k)$. However, they have very high acoustic impedance and they are very brittle which affects fabrication. For this reason fiber piezocomposites are developed by combination of piezoceramics and polymers from the piezocomposites. These composites have shown remarkable improvement in the performance of ultrasonic devices over their counterparts like piezoceramics and piezopolymers with their tailor-made properties. They have suitable material properties for transducer applications such as moderate electromechanical coefficients, low acoustic impedance and low density, wide range of dielectric constants, low dielectric loss and low mechanical loss [2].

Variety of piezocomposite materials can be made by combining a piezoceramic with a passive polymer such as epoxy or active polymer such as PVDF [3]. The piezocomposites are classified according to their connectivity (such as 2-2, 1-3, 0-3 etc.,). Connectivity is defined as the number of dimensions through which the material is continuous [4]. It is conventional for the first digit to refer to the piezoelectrically active phase. These achievements are made possible with enormous research in the design and investigation of the piezocomposite materials. Experimental work done

\footnotetext{
*E-mail: cvm_rao@rediffmail.com

†E-mail: gudurup@osmania.ac.in
} 
in the fabrication of piezocomposites, with 2-2 and 1-3 connectivity, lead to ultra-fine technologies in their manufacturing process [5 -8]. Presently, piezocomposites in the form of layers of a few micrometers thick and fibers of a few a micrometers diameter are fabricated with the advancement in the manufacturing technologies. The field of MEMS (Micro-Electro-Mechanical Systems) has grown in leaps and bounds with this advent. The study of micromechanics of piezocomposites, with their effective material properties in focus, resulted in more careful choice of materials for specific purposes [9]. Optimization of the device performance is achieved by both simulation and experimental evaluation methods [10]. The most commonly used method for designing composite transducer devices is the effective medium model proposed by Smith [11 13]. The effective medium theory predicts the material properties of the composites based on the volume fraction of the piezoceramic enclosed in the soft matrix medium. However, the aspect ratio of the fibers (aspect ratio is defined as $a / l$, where $a$ is the diameter and $l$ is the length of fibers) is not included in the analytical equations derived by Smith et.al. For this reason FEM is adopted to study the effect of aspect ratio on the material properties of composite which can be used in transducer design.

A brief description of piezocomposites is presented in the first section. The constitutive equations related to piezoelectric materials are discussed in the second section. Details of finite element modeling are then presented in the third section. In the present study an attempt is made to determine the material coefficients which are important in biomedical transducers. A step by step approach is presented and discussed in the fourth section. The important conclusions drawn are presented in the last section.

\section{Piezoelectric 1-3 composites}

Composite materials have applications in transducers for pulse echo medical ultrasonic imaging. There are several requirements for piezoelectric used in these transducers. First, for sensitive transducers, the piezoelectric should convert between electric and mechanical energy. Second, the piezoelectric should be acoustically matched to tissue so that acoustic waves couple well in the transducer and tissue both during transmission and reception. Third, the electric properties should be compatible with the driving and receiving electronics. The requirement of relevant parameters on high electromechanical coupling coefficient $\left(k_{t} \rightarrow 1\right)$, acoustic impedance close to tissue $(Z \rightarrow 1.5$ Mrayls), large dielectric constant $(\geqslant 100)$, low dielectric loss $(\tan \delta<0.05)$ and low mechanical $\operatorname{loss}\left(Q_{m} \geqslant 10\right)[13]$.

Polymer piezoelectric composites with 1-3 connectivity can meet many of these stringent requirements. In this paper we report a detailed finite element analysis using a unit cell model for thickness mode vibrations. The results obtained are compared with the analytical and experimental results. The agreement between the results better proves the validity of the method of simulation.

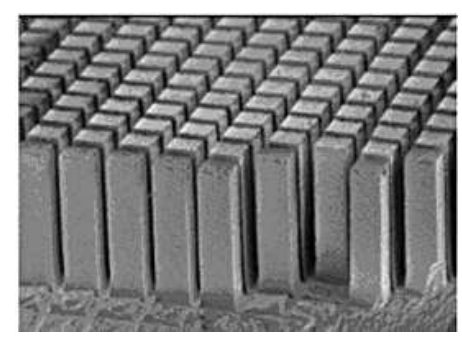

Figure 1. Rectangular piezoceramic fibers in square arrangement [14].

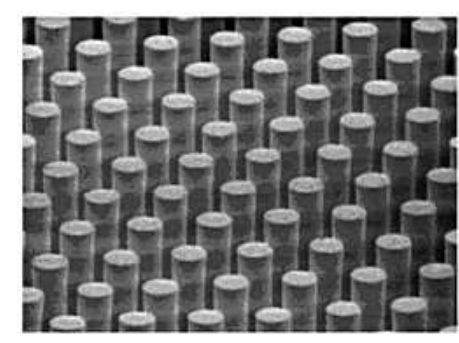

Figure 2. Cylindrical piezoceramic fibers in hexagonal arrangement [7].

Piezoelectric 1-3 composites are formed by embedding piezoelectric ceramic fibers in a passive polymer medium. The ceramic fibers may have a square or circular cross section. They may be arranged in square or hexagonal arrangement as shown in figures 1 and 2, The rod composite geometry provides materials with enhanced electromechanical coupling and with acoustic impedance 
close to that of biological tissue; these advantages yield transducers for medical ultrasonic imaging with high sensitivity and compact impulse response. Proper design of the rod spacing (lateral fine scale spacing) yields materials which exhibit low cross-talk between array elements formed by patterning the electrode alone, without cutting between the elements. Keeping this in view, fiber composites having very fine fiber diameter $(\sim 40$ micrometer $)$ are analyzed.

\section{Piezoelectric constitutive equations}

Piezoelectricity is a coupling between a material's mechanical and electrical behavior, which can be represented by the following constitutive equations in tensor notation. $T_{i j}$ Stress, $S_{k l}$ strain, electric field $E_{k}$ and electric displacement $D_{i}$ are related by equation (1)

$$
\begin{gathered}
T_{i j}=c_{i j k l}^{E} S_{k l}-e_{k i j}^{t} E_{k}, \\
D_{i}=e_{k i j} S_{k l}+\varepsilon_{j k}^{S} E_{k},
\end{gathered}
$$

where $c_{i j k l}^{E}$ is a fourth-order elasticity tensor under short circuit boundary conditions. $\varepsilon_{i k}^{S}$ is a second-order free body dielectric tensor and $e_{k i j}$ is a third-order piezoelectric strain tensor. Due to symmetry of the tensors $T_{i j}, S_{k l}, c_{i j k l}^{E}$ and $\varepsilon_{i k}^{S}$, the above equation (11) can be written in the matrix notation as equation (2) as follows.

$$
\left[\begin{array}{l}
T \\
D
\end{array}\right]=\left[\begin{array}{cc}
C^{E} & -e^{t} \\
e & \varepsilon^{S}
\end{array}\right]\left[\begin{array}{l}
S \\
E
\end{array}\right],
$$

where $t$ denotes a transposed matrix.

For a transversely isotropic piezoelectric material, the stiffness matrix, the piezoelectric matrix and the dielectric matrix simplify so that 7 of the orthotropic constants depend on the others as given below and only 11 independent coefficients are to be determined.

$$
\begin{aligned}
& c_{22}=c_{11}, \quad c_{23}=c_{13}, \quad c_{55}=c_{44}, \quad c_{66}=\left(c_{11}-c_{12}\right) / 2, \\
& e_{24}=e_{15}, \quad e_{32}=e_{31}, \quad \epsilon_{22}=\epsilon_{11} \text {. }
\end{aligned}
$$

Therefore, the constitutive equation (1) can be written as follows.

$$
\left[\begin{array}{c}
\bar{T}_{11} \\
\bar{T}_{22} \\
\bar{T}_{33} \\
\bar{T}_{23} \\
\bar{T}_{31} \\
\bar{T}_{12} \\
\bar{D}_{1} \\
\bar{D}_{2} \\
\bar{D}_{3}
\end{array}\right]=\left[\begin{array}{ccccccccc}
C_{11}^{e f f} & C_{12}^{\text {eff }} & C_{13}^{\text {eff }} & 0 & 0 & 0 & 0 & 0 & -e_{13}^{\text {eff }} \\
C_{12}^{\text {eff }} & C_{11}^{\text {eff }} & C_{13}^{\text {eff }} & 0 & 0 & 0 & 0 & 0 & -e_{13}^{\text {eff }} \\
C_{13}^{\text {eff }} & C_{13}^{\text {eff }} & C_{33}^{\text {eff }} & 0 & 0 & 0 & 0 & 0 & -e_{33}^{\text {eff }} \\
0 & 0 & 0 & C_{44}^{\text {eff }} & 0 & 0 & 0 & -e_{15}^{\text {eff }} & 0 \\
0 & 0 & 0 & 0 & C_{44}^{\text {eff }} & 0 & -e_{15}^{\text {eff }} & 0 & 0 \\
0 & 0 & 0 & 0 & 0 & C_{66}^{e f f} & 0 & 0 & 0 \\
0 & 0 & 0 & 0 & e_{15}^{\text {eff }} & 0 & \varepsilon_{11}^{\text {eff }} & 0 & 0 \\
0 & 0 & 0 & e_{15}^{\text {eff }} & 0 & 0 & 0 & \varepsilon_{11}^{\text {eff }} & 0 \\
e_{13}^{e f f} & e_{13}^{\text {eff }} & e_{33}^{\text {eff }} & 0 & 0 & 0 & 0 & 0 & \varepsilon_{33}^{\text {eff }}
\end{array}\right]\left[\begin{array}{c}
\bar{S}_{11} \\
\bar{S}_{22} \\
\bar{S}_{33} \\
\bar{S}_{23} \\
\bar{S}_{31} \\
\bar{S}_{12} \\
\bar{E}_{1} \\
\bar{E}_{2} \\
\bar{E}_{3}
\end{array}\right] .
$$

A bar on $T, S, E$ and $D$ indicates average values and the piezoelectric coefficients are the effective properties of the composite structure as indicated by the superscript. These equations are further used in numerical evaluation process.

\section{Analytical equations}

The effective properties of the piezocomposite which are more relevant in thickness mode vibrations are given by below equations (6) -(17) where all the parameters are represented by IEEE standard notations 13. The volume fraction of the inclusion piezoceramic fiber material in the 
composite is represented by $\nu$ and the volume fraction of the matrix material is represented by $\bar{\nu}$, where

$$
\bar{\nu}=(1-\nu) .
$$

The mean elastic constants are given by:

$$
\begin{aligned}
\bar{c}_{13}^{E} & =\frac{\nu c_{13}^{E}\left(c_{11}+c_{12}\right)+\bar{\nu} c_{12}\left(c_{11}^{E}+c_{12}^{E}\right)}{\nu\left(c_{11}+c_{12}\right)+\bar{\nu}\left(c_{11}^{E}+c_{12}^{E}\right)} \\
\bar{c}_{33}^{E} & =\nu\left[c_{33}^{E}-\frac{2 \bar{\nu}\left(c_{13}^{E}-c_{12}\right)^{2}}{\nu\left(c_{11}+c_{12}\right)+\bar{\nu}\left(c_{11}^{E}+c_{12}^{E}\right)}\right]+\bar{\nu} c_{11} .
\end{aligned}
$$

The average electromechanical coefficients are given by:

$$
\begin{aligned}
\overline{e_{31}} & =\frac{\nu e_{31}\left(c_{11}+c_{12}\right)}{\nu\left(c_{11}+c_{12}\right)+\bar{\nu}\left(c_{11}^{E}+c_{12}^{E}\right)}, \\
\overline{e_{33}} & =\nu\left[e_{33}-\frac{2 \bar{\nu} e_{31}\left(c_{13}^{E}-c_{12}\right)}{\nu\left(c_{11}+c_{12}\right)+\bar{\nu} c_{11}^{E}+c_{12}^{E}}\right] .
\end{aligned}
$$

The average static dielectric constant is:

$$
\bar{\varepsilon}_{33}^{S}=\nu\left[\varepsilon_{33}^{S}+\frac{2 \bar{\nu}\left(e_{31}\right)^{2}}{\nu\left(c_{11}+c_{12}\right)+\bar{\nu}\left(c_{11}^{E}+c_{12}^{E}\right)}\right]+\bar{\nu} \varepsilon_{11} .
$$

From the above, one can calculate:

$$
\bar{c}_{33}^{D}=\bar{c}_{33}^{E}+\left(\bar{e}_{33}\right)^{2} / \bar{\varepsilon}_{33}^{S} .
$$

Piezoelectric $h$ constant is given by:

$$
\bar{h}_{33}=\frac{\bar{e}_{33}}{\bar{\varepsilon}_{33}^{S}} .
$$

The dielectric susceptibility is inverse of permittivity and given by:

$$
\bar{\beta}_{33}^{S}=\frac{1}{\bar{\varepsilon}_{33}^{S}}
$$

The average density of composite depends on densities of polymer $(\rho p)$ and density of ceramic $(\rho c)$ by:

$$
\bar{\rho}=\nu \rho^{c}+\bar{\nu} \rho^{p}
$$

The average electromechanical coupling coefficient is given by:

$$
\bar{k}_{t}=\bar{h}_{33} /\left(\bar{c}_{33}^{D} \bar{\beta}_{33}^{S}\right)^{1 / 2}=\bar{e}_{33} /\left(\bar{c}_{33}^{D} \bar{\varepsilon}_{33}^{S}\right)^{1 / 2} .
$$

Acoustic impedance is given by

$$
\bar{z}=\left(\bar{c}_{33}^{D} \bar{\rho}\right)^{1 / 2}
$$

Longitudinal acoustic velocity is given by:

$$
\bar{v}_{l}=\left(\bar{c}_{33}^{D} / \bar{\rho}\right)^{1 / 2} .
$$

Using the above equations and the values of component phase parameters, average values of composite parameters are calculated and plotted. 


\section{Numerical evaluation - implementation of finite element method}

A full model of composite is difficult to analyze because of the constraints such as limited processing speed and memory available for computation of computing devices. Therefore, for simplicity, a periodic array of cylindrical fibers with square arrangement is considered as shown in figure 3. This periodic nature of fibers in the composite allows us to select a simple volume element which represents the general characteristics of the whole composite. This volume element is also called a unit cell as shown in figure 4. It is this volume element that we consider for analysis by applying periodic boundary conditions. The complete description of the evaluation of effective material properties by simulation can be found in [15].

The boundary conditions that are applied to the unit cell to evaluate various effective material properties are briefly described as follows.

- To apply strain in $\mathrm{X}_{3-}$ direction, predefined displacements are applied perpendicularly on $\mathrm{C}^{+}$plane on all nodes. At the same time, zero displacements are applied on $\mathrm{C}^{-}$plane.

- To apply pure shear stress in $\mathrm{X}_{1} \mathrm{X}_{2}$-plane, tangential forces are applied on all nodes on $\mathrm{A}^{+}$ and $\mathrm{B}^{+}$planes while constraining the displacement of nodes along $\mathrm{X}_{3}$-direction.

- To apply electric field along $\mathrm{X}_{3}$-direction, $\mathrm{C}^{-}$plane is kept at zero potential while a non-zero potential is applied on $\mathrm{C}^{+}$plane.

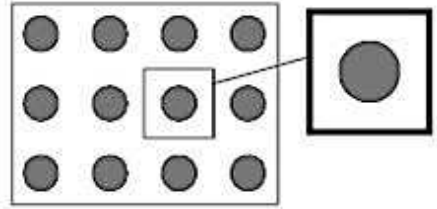

Figure 3. Unit cells for square arrangement of fibers.

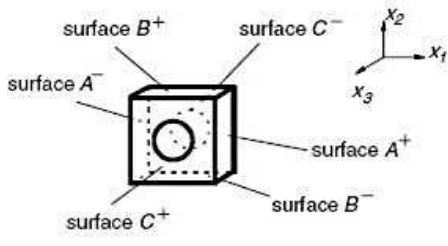

Figure 4. Notations for identifying surfaces of the unit cell.

The effective properties of the piezocomposite can be extracted by solving the matrix equations given by equation (4). We solve these equations simultaneously by applying appropriate boundary conditions so that only one equation is set to give a non-zero result while all others vanish. For example to evaluate $e_{33}^{\text {eff }}$, the following boundary conditions are applied.

- Apply zero normal displacements to all surfaces so that all the strain terms become zero.

- Apply zero potential at $\mathrm{C}^{-}$plane and a non-zero potential on $\mathrm{C}^{+}$plane so that an electric field exists along Z-direction.

- Apply zero potential at all other planes so that no electric field exists along X and Ydirections.

After the above boundary conditions are applied, $e_{33}^{\text {eff }}$ is calculated as $e_{33}^{\text {eff }}=-T_{33} / E_{33}$. All the other effective properties are extracted by applying suitable boundary conditions.

Following Smith's analytical model as given in [11], Chan et. al. [12] derived the analytical equations for the effective material properties of 1-3 piezocomposites. They also experimentally checked the validity of their equations for various physical quantities for different volume fractions of piezoceramic in the composite material. The coincidence between the theoretical and the reported experimental values is quite appreciable. Analytical, numerical and experimental values are compared for PZT 7A - Araldite D composites. Model's predictions and their implications for transducer applications are considered.

As a part of the analysis, the unit cell of 1-3 piezocomposite is modeled with the fiber material made of PZT 7A which is included in an Araldite D matrix. The effective properties of the 
piezocomposite which are more relevant in thickness mode vibrations are extracted by simulating the unit cell of the 1-3 composite and performing the static analysis by ANSYS software and they are compared with the analytical and experimental results following Smith's equations [13]. The material properties of PZT 7A and Araldite D are taken from [12]. To check the correctness of the model, the effective material properties of the composite, namely, $c_{33}, e_{33}$ and $\varepsilon_{33}$ are determined for different volume fractions of fiber material in the composite by simulation.

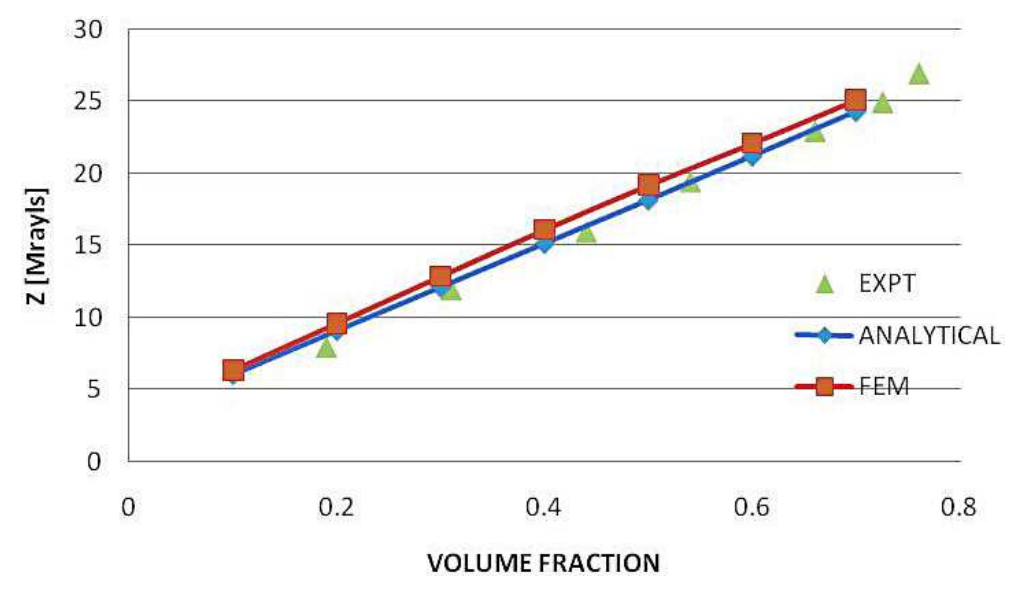

Figure 5. Variation of Acoustic Impedance with volume fraction.

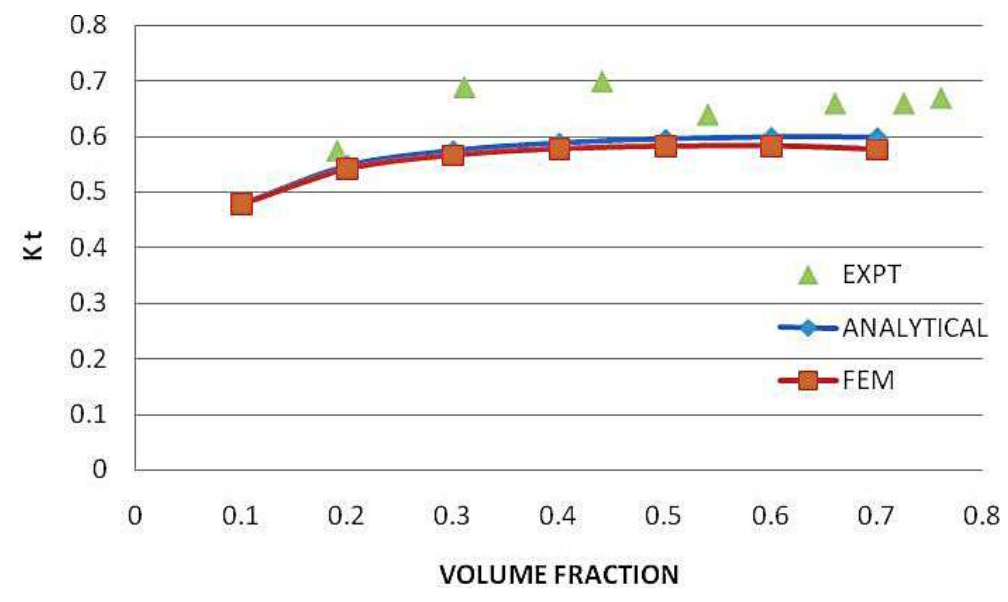

Figure 6. Variation of $k_{t}$ with volume fraction.

It is found that the effective properties $c_{33}, e_{33}$ and $\varepsilon_{33}$ linearly vary with volume fraction. From these values the effective transducer parameters, namely, the electromechanical coupling coefficient, $k_{t}$, the acoustic impedance $Z$ and the longitudinal velocity $V_{l}$ are determined using equations given in section 3. These simulation results are shown graphically in figures 5 along with the analytical results following Smith's model. Experimental values are provided for comparison wherever they are available. The experimental values are taken from [12]. Evidently the simulation results are in close agreement with the analytical and experimental values. In the graphs, the results obtained by simulation are indicated by the label FEM and the values that are calculated by using the analytical equation presented in section 3 are indicated by the label ANALYTICAL. The experimental values are indicated by the label EXPT.

In figure 5 it can be noted that the acoustic impedance increases linearly with the increase of volume fraction. At lower volume fractions, the variation is almost linear but at higher volume 
fractions the variation shows non-linear behavior as we observe the numerical results while the analytical solution predicts completely linear behavior.

In figure 6 it can be noted that the thickness mode electromechanical coupling coefficient, $k_{t}$ increases with the volume fraction because the electrical energy is more efficiently converted into mechanical energy. There is a close agreement between the simulated and analytical results at all volume fractions.

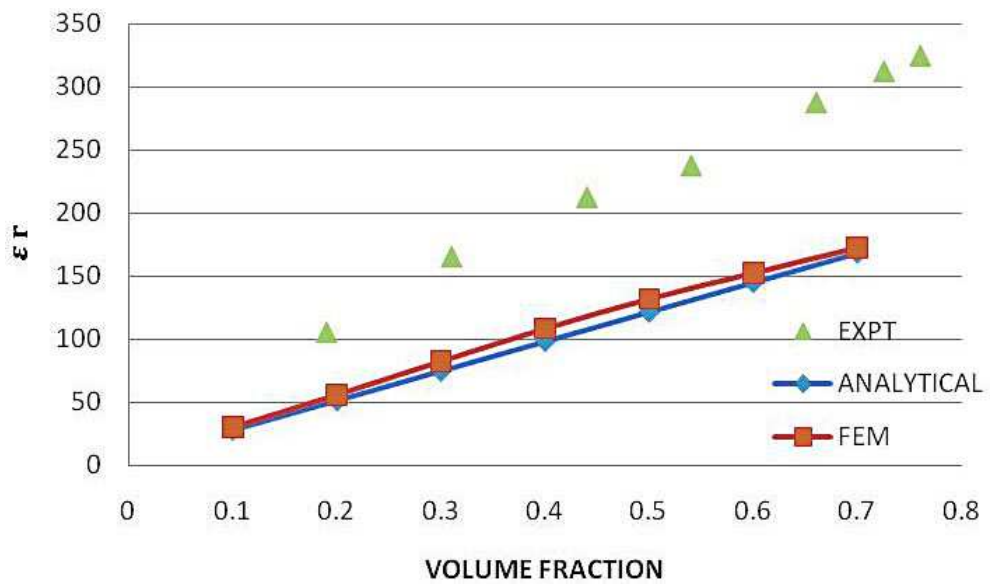

Figure 7. Variation of Relative permittivity with volume fraction.

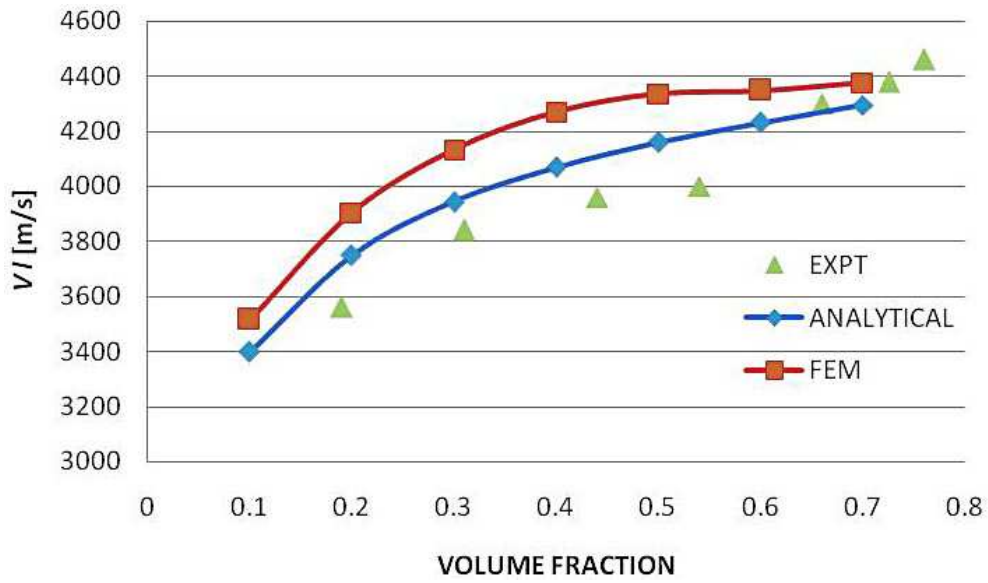

Figure 8. Variation of Longitudinal velocity with volume fraction.

In figure 7, two types of the relative permittivity values are shown. The values obtained by simulation and by analytical equations are of type $\varepsilon^{S}$ and the experimental values are of type $\varepsilon^{T}$. The effect of internal field modifications is not taken into considerations resulting in the deviation of simulated and experimental values of dielectric constant. However, the dielectric constant values obtained from analytical and numerical methods agree very well.

As the volume fraction becomes larger, the subsequent clamping of fibers by polymer has an appreciable effect on the elastic and piezoelectric behavior; the elastic stiffness $c_{33}$ is expected to increase and piezoelectric strain constant $e_{33}$ decreases. However, in the present work this kind of clamping is not observed even up to 0.70 volume fraction. As the volume fraction increases, the stiffening effect of adding more ceramic is mass loading (increased density) and this is responsible for saturation effects observed in $k_{t}$ (figure 6) and $V_{l}$ (figure 7).

The structural dimensions of a composite depend on the operating frequencies of the transducer. 


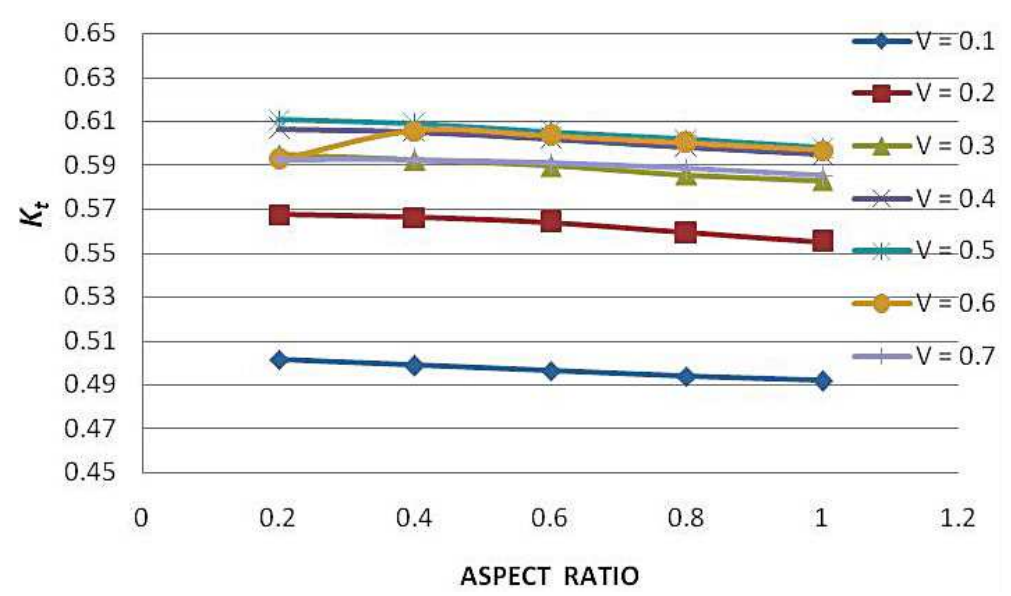

Figure 9. Variation of $k_{t}$ with aspect ratio.

The height of individual fiber is proportional to the ratio of the operating frequency and the frequency constant of the ceramic. Hence, aspect ratio (height/width) is an important parameter to be considered.

The dependence of $k_{t}$ on the aspect ratio of the piezoceramic fibers is also studied by simulation for various volume fractions of piezoceramic fibers in the composite and the results are shown graphically in figure 9 .

Table 1. Comparison of Analytical and FEM results for $a / l=0.2$.

\begin{tabular}{|l|l|l|l|l|l|l|l|l|l|l|}
\hline$\nu$ & & $\begin{array}{l}C_{13} \\
(\mathrm{GPa})\end{array}$ & $\begin{array}{l}C_{33} \\
(\mathrm{GPa})\end{array}$ & $\begin{array}{l}e_{31} \\
(\mathrm{C} / \mathrm{m} 2)\end{array}$ & $\begin{array}{l}e_{33} \\
(\mathrm{C} / \mathrm{m} 2)\end{array}$ & $\begin{array}{l}\varepsilon_{33} \\
(\mathrm{nF} / \mathrm{m})\end{array}$ & $\varepsilon_{r 33}$ & $k_{t}$ & $\begin{array}{l}V_{l} \\
(\mathrm{~m} / \mathrm{s})\end{array}$ & $\begin{array}{l}Z \\
(\mathrm{Mrayl})\end{array}$ \\
\hline 0.1 & $\mathrm{~A}$ & 4.90 & 13.2 & -0.0364 & 1.854 & 0.796 & 89.9425 & 0.4963 & 3150 & 5.56 \\
\hline & $\mathrm{F}$ & 5.15 & 13.9 & -0.0690 & 2.0142 & 0.869 & 98.1364 & 0.5014 & 3240 & 5.72 \\
\hline 0.2 & $\mathrm{~A}$ & 5.51 & 18.5 & -0.0813 & 3.7016 & 1.55 & 175.6275 & 0.5679 & 3350 & 8.15 \\
\hline & $\mathrm{F}$ & 5.99 & 19.8 & -0.1509 & 3.9747 & 1.68 & 190.3059 & 0.5675 & 3470 & 8.42 \\
\hline 0.3 & $\mathrm{~A}$ & 6.27 & 23.9 & -0.1378 & 5.5401 & 2.31 & 261.2375 & 0.5972 & 3470 & 10.7 \\
\hline & $\mathrm{F}$ & 7.02 & 25.8 & -0.2508 & 5.9402 & 2.50 & 282.8398 & 0.5947 & 3590 & 11.1 \\
\hline 0.4 & $\mathrm{~A}$ & 7.27 & 29.5 & -0.2113 & 7.3655 & 3.07 & 346.7387 & 0.6118 & 3540 & 13.3 \\
\hline & $\mathrm{F}$ & 8.40 & 32.0 & -0.3793 & 7.8511 & 3.31 & 374.0547 & 0.6065 & 3670 & 13.8 \\
\hline 0.5 & $\mathrm{~A}$ & 8.62 & 35.4 & -0.3106 & 9.1709 & 3.82 & 432.0735 & 0.6189 & 3600 & 15.9 \\
\hline & $\mathrm{F}$ & 10.5 & 39.0 & -0.5746 & 9.7955 & 4.14 & 467.9055 & 0.6105 & 3750 & 16.6 \\
\hline 0.6 & $\mathrm{~A}$ & 10.6 & 41.7 & -0.4524 & 10.9435 & 4.58 & 517.1354 & 0.6207 & 3650 & 18.6 \\
\hline & $\mathrm{F}$ & 13.1 & 44.9 & -0.7723 & 11.067 & 4.71 & 532.5207 & 0.6065 & 4370 & 16.4 \\
\hline 0.7 & $\mathrm{~A}$ & 13.5 & 48.9 & -0.6713 & 12.6564 & 5.33 & 601.7016 & 0.6172 & 3700 & 21.3 \\
\hline & $\mathrm{F}$ & 18.6 & 53.5 & -1.2282 & 12.4977 & 5.40 & 610.2610 & 0.5924 & 4680 & 17.6 \\
\hline
\end{tabular}

A: Analytical values; F: Finite Element values.

From figure 9 it can be noted that, for a fixed volume fraction of the ceramic, the electromechanical coupling coefficient $\left(k_{t}\right)$ decreases with the increase of the aspect ratio of the fiber. Therefore, it can be noted that for higher values of $k_{t}$, higher volume fraction of fiber material is required and at the same time the aspect ratio of the fibers should be small. This behavior is useful in optimizing the transducer performance. This result follows from the fact that the effective elastic coefficient $\left(c_{33}\right)$ of the composite increased with the increase in the aspect ratio of the fibers, although the other two quantities $\left(c_{33}\right.$ and $\left.\varepsilon_{33}\right)$ remain almost unchanged.

To make sensitive transducers, an essential requirement is low $Z$ and high $k_{t}$. The present calculations show that 1-3 composites can be superior in both respects; trade off being between 
minimizing impedance and maximizing coupling. This is because the lowering volume fraction lowers not only $Z$ but also the coupling.

For comparison of simulation results with analytical results for $a / l=0.2$, the results are given in table 1.

From the graphs, it can be observed that the analytical results obtained from effective medium theory and the results obtained from FEM are in close agreement at all volume fractions. The thickness mode electromechanical coupling coefficient $\left(k_{t}\right)$ is a very important transducer parameter which we seek to be as high as possible. From figure 6 it can be observed that for $\nu=0.6, k_{t}$ almost reaches its maximum possible value. That means we can achieve the same value of $k_{t}$ even by reducing the content of piezoceramic by 40 percent. This effort results in lower density of the composite material.

Another important requirement of a piezocomposite to be used in a transducer is the low acoustic impedance $(Z)$. From figure 5 it is noted that the acoustic impedance can be reduced by reducing the volume content of piezoceramic (i.e. by reducing the volume fraction of piezoceramic, $\nu)$ in the piezocomposite. At the same time, $k_{t}$ decreases with the decrease in $\nu$, which we do not need. Therefore, a tradeoff should be made between $k_{t}$ and $Z$ for optimal performance of transducer.

For better performance of a 1-3 composite transducer, there should be an effective transfer of stress between the fiber material and the matrix material for which the surface area of interaction should be made as large as possible [16]. This can be achieved by selecting long narrow fibers which has lower aspect ratio $(a / l)$ of fiber. We have also shown by the simulation results how the aspect ratio of fibers affects the effective elastic coefficients and hence $k_{t}$. These results prompt us to select piezoceramic fibers with lower aspect ratio for higher $k_{t}$ values. By these trends the demand for narrow fiber diameters increases which require high end technologies in the manufacturing process of 1-3 piezocomposites [7, 17-21].

\section{Conclusions}

A framework has been worked out for simulation of essential ultrasonic transducer parameters required for the composite transducer in medical or biological applications. The variations of these parameters with aspect ratio are also worked out. The results are compared with experimental and analytical values.

The effect of aspect ratio $(a / l)$ on the effective properties of the 1-3 composite is not included in the Smith's analytical equation. However, when we analyzed the effect of $(a / l)$ by simulation, it turned out that the effective properties are more sensitive to $(a / l)$ only at higher volume fractions. It can also be noted that the relative permittivity is almost independent of $(a / l)$ at all volume fractions.

In the present work, piezoelectric fiber composites are modeled and analyzed by ANSYS software by performing static analysis. The effective material properties of piezoceramic polymer composites with 1-3 connectivity are determined. The dependence of the effective material properties on the volume fraction of piezoceramic in the composite is analyzed by numerical results and then the results are verified by using analytical equations. It is also noted that the fiber aspect ratio $(a / l)$ also effects the composite material properties at higher volume fractions. The results are shown graphically for comparison. These results are useful in characterizing the piezocomposite materials. The simulation procedure adopted is also useful in optimizing the material properties of 1-3 piezocomposites which are used in biomedical transducer applications. The simulation procedure developed eliminates the trial and error method of optimization of piezocomposite transducer materials. More importantly, optimization of aspect ratio for better $k_{t}$ is achieved which is not covered by the Smith's model. Another advantage of simulation model is that different combinations of piezoceramic fibers (with different $a / l$ ) and polymer matrix (piezo or non-piezo) materials can be easily worked out without the use of any kind of laborious analytical procedures, the accuracy being limited to the fineness of the model. 


\title{
References
}

1. Smith W.A. - In: Proc. of the 1989 IEEE Ulrrasonics Symposium, Montreal, Quebec, Canada, 3-6 October, 1989.

2. Gururaja T. R., Schulze W. A., Cross L. E., Newnham R. E., Auld B. A., Wang Y. J., IEEE T. Son. Ultrason., 1985, 32, 481-498.

3. Kin Wing Kwok, Helen Lai Wah Chan, Chung Loong Choy, IEEE T. Ultrason. Ferr., 1999, 46, No. 3.

4. Newnham R. E., Skinner D. P., Cross L. E., Mater. Res. Bull., 1978, 13, 525-536.

5. Near C., Schmidt G., McNeal K., Gentilman R., SPIE, 1998, 3326, 323-331.

6. Safari A., J. Phys. III France, 1994, 4, 1129-1149.

7. Gebhardt S., Schönecker A., Steinhausen R., Hauke T., Seifert W., Beige H., Ferroelectrics, 2000, 241, 67-73.

8. Zhang D., Nelson L.J., Dent A., MacLennan D., Meggs C., Dolman G., Su B., Cochran S., Kirk K.J., Bowen C.R., Button T.W., Fine Scale Lead Zirconate Titanate (PZT) Fibres and Composite Structures. University of Bath, http://www.fmg.bham.ac.uk.

9. Iker F., André N., Proost J., Pardoen T., Raskin J.P., Fabrication and modeling of 3-D self-assembled SOI MEMS using plasticity features. - In: Proc., 18th IEEE International Conference on Micro Electro Mechanical Systems - MEMS 2005. Miami, USA, 2005, p. 459-462.

10. Nelli Silva E.C., Ono Fonseca J.S., Kikuchi N., Computational Mechanics, 1997, 19, 397-410.

11. Smith W.A., Shaulov A., Auld B.A., Tailoring the properties of composite piezoelectric materials for medical ultrasonic transducers. - In: Proc., IEEE Ulfrason. Symp., 1985, p. 642-647.

12. Wah Chan H.L., Unsworth J., IEEE T. Ultrason. Ferr., 1989, 36, No. 4.

13. Smith W.A., Auld B.A., IEEE T. Ultrason. Ferr., 1991, 38, No. 1.

14. Steinhausen R., Charakterisierung und Modellierung piezoelektrischer 1-3 Komposite. Dissertation Martin-Luther-University, Halle, Germany, 2002.

15. Berger H., Kari S., Gabbert U., Rodriguez-Ramos R., Guinovart R., Otero J.A., Bravo-Castillero J., Int. J. Solids Struct., 2005, 42, 5692-5714.

16. Wenwu Cao, Zhang Q.M., Cross L.E., J. Appl. Phys., 1992, 72 (12), 15.

17. Janas V.F., Safari A., J. Am. Ceram. Soc., 1995, 78, No. 11, 2945-2955.

18. Gebhardt S., Schoenecker A., Steinhausen R., Seifert W., Beige H., J. Eur. Ceram. Soc., 2003, 23, 153-159.

19. Glaubitt W., Watzka W., Scholz H., Sporn D., J. Sol-Gel Sci. Technol., 1997, 8, 29-33.

20. Steinhausen R., Hauke T., Beige H., Watzka W., Lange U., Sporn D., Gebhardt S., Schoenecker A., J. Eur. Ceram. Soc., 2001, 21, 1459-1462.

21. Klicker K.A., Piezoelectric composite with 3-1 connectivity for transducer applications. Ph.D. Thesis, Solid State Science, The Pennsylvania State Univ., 1981.

\section{Характеристика 1-3 п'єзоелектричних полімерних композитів - числова і аналітична процедура оцінки вібрацій мод товщини}

\author{
С.В. Мадгусудгана Рао, Г. Прасад \\ Університет Османіа, Гайдерабад 500004 A.P, Індія
}

Біомедичні датчики широко використовують п'єзокерамічні полімерні композити з 1-3 зв'язністю. Дослідження націлене на визначення ефективних матеріальних властивостей цих композитів на мікрометричних масштабах методами комп'ютерного моделювання. Як було вже показано, об'ємна доля п'єзокераміки в композиті відіграє важливу роль у властивостях композитного матеріалу. Потрібно також відзначити вплив коефіцієнта волокнистості $(a / l)$ на матеріальні властивості композита. Отже, метою є визначення ефективних матеріальних властивостей, використовуючи як аналітичні методи, так і комп'ютерне моделювання, а саме, програму ANSYS, яка базується на методі скінченого елемента (FEM). У даній роботі моделюються та аналізуються п'єзоелектричні волокнисті композити, а отримані результати перевіряються з використанням аналітичних рівнянь. Зроблено важливі висновки щодо виділення п'єзокомпозитних матеріалів для застосування у датчиках.

Ключові слова: п'єзоелектричність, п'єзоелектричні матеріали, електромеханічні ефекти, п'єзоелектричні датчики, методи скінченого елементу 